\title{
Cidade moderna, homem melancólico: uma leitura de Onde andará Dulce Veiga?
}

\section{Luana Teixeira Porto*}

\begin{abstract}
Resumo: Este trabalho consiste em uma leitura da obra Onde andará Dulce Veiga?, de Caio Fernando Abreu, publicada em 1996. O objetivo da pesquisa é desenvolver uma leitura crítica do romance que englobe uma articulação entre forma literária e conteúdo social, melancolia e cidade moderna.
\end{abstract}

\begin{abstract}
This paper is a reading possibility of Onde andará Dulce Veiga?, by Caio Fernando Abreu, published in 1996. The objective of the research is to develop a critical reading of the novel which considers an articulation between the literary form, the social content, melancholy and the modern city.
\end{abstract}

Palavras-chave: fragmentação, melancolia; cidade moderna; Onde andará Dulce Veiga?
Keywords: fragmentation; melancholy; modern city; Onde andará Dulce Veiga?

A ficção brasileira contemporânea tem problematizado a experiência urbana na modernidade, acentuando temas como vivência do choque, fragmentação do sujeito, indiferença como forma de defesa em relação a estímulos externos, imagem da rua como símbolo da excitação e da animação urbanas de acordo com Renato Cordeiro Gomes (2000). A isso se acrescenta a representação da cidade como um espaço onde se evidenciam contradições do mundo moderno, o choque e a desestruturação do indivíduo, a instabilidade urbana, que atinge não só a paisagem geográfica, a arquitetura e a economia da cidade, mas também a interioridade do sujeito.

O romance Onde andará Dulce Veiga?, de Caio Fernando Abreu - classificado por Antônio Hohlfeldt como um romance "curioso" visto quebrar a "tradição dos textos anteriores do escritor" (1996, p. 120) - é representativo de uma literatura que discute a vida moderna e suscita uma leitura da realidade urbana. Esta, tal como sublinha Renato Cordeiro Gomes, mostra que "o presente turbulento por onde campeia a violência circunscreve a cidade enquanto morada incerta e inevitável" (GOMES, 2000, p. 68). O personagem principal do romance, um jornalista que assume um papel de detetive para encontrar uma cantora desaparecida, é também o narrador da história. Morador da cidade de São Paulo, a maior

\footnotetext{
* Doutoranda.
} 
metrópole brasileira, ele parece sintetizar a impressão corrente dos grandes espaços urbanos, pois, para ele, São Paulo é uma "cidade infernal” (ABREU, 1990, p. 11) e a vivência neste ambiente o sufoca e o faz buscar a sua própria identidade. Uma busca que está camuflada na procura por Dulce Veiga, a artista que há tempos havia sumido e deixado seus fãs sem notícias.

O narrador-personagem acentua não só a precariedade da experiência pessoal na cidade e as dificuldades de sobrevivência que assolam o cotidiano do indivíduo moderno que vive nas metrópoles e que o colocam em posição marginal, mas também evidencia um espaço urbano que condensa movimentos antagônicos de criação e desconstrução, os quais atingem a subjetividade. Por isso, é possível perceber um movimento duplo na construção do romance, já que a cidade é apresentada e projetada através da ótica do protagonista, que, por sua vez, incorpora e expõe as fragilidades e ambigüidades do ambiente urbano. Nessa perspectiva, este ensaio discute a possibilidade de se reconhecer no narrador-protagonista de Caio Fernando Abreu um leitor da cidade e também um tipo humano da modernidade representativo do ser que vive nas cidades. Assim, parte-se do princípio de que, por ser um leitor do espaço urbano e vivenciar as incertezas da cidade, o protagonista exterioriza um mal-estar que acarreta crise da subjetividade e melancolia. E tais conseqüências são observadas via enredo e forma narrativa no sentido de que a perspectiva melancólica e a crise do sujeito encontram eco na estrutura e linguagem literária, as quais se caracterizam pela fragmentação do discurso.

\section{0 leitor da cidade}

A caracterização da cidade como um espaço propício para a marginalização e a exclusão social já é sugerida na abertura do romance. O jornalista inicia seu relato. contando um "milagre" que acontecera em sua vida: tinha conseguido um emprego (ou melhor, um "subemprego") "capaz de trazer alguma paz àquela série de solavancos sem rumo nem ritmo" (ABREU, 1990, p. 12) que ele estava habituado a chamar de sua 'vida', uma vida, que como será destacado mais adiante, é repleta de sentimentos de perda e melancolia. Esta perspectiva já pode ser identificada no modo como o narrador define a sua condição vital, pois o termo "solavancos", no contexto da narrativa, assume um significado maior, deixando de se limitar apenas aos trancos ou socos bruscos a que se costuma atribuir ao vocábulo para indicar os percalços por que passa o personagem. Isso faz uma alusão às dificuldades de sobrevivência que encontra, já que não vem de família abastada, não tem grande patrimônio nem dinheiro que propicie uma vida confortável. 
Além das dificuldades de ordem material, o protagonista enfrenta a solidão e a experiência de viver numa cidade sombria, cujo movimento inquietante e constante é, segundo o próprio narrador-personagem, cortado pelas paredes do prédio de seu apartamento. É como se houvesse uma separação entre espaço coletivo (o da cidade) e espaço privado (o da moradia do protagonista), da qual parece estar subjacente uma hierarquia que valoriza o ambiente interno como um ambiente alheio à euforia e à desorganização da cidade e que desprivilegia o contexto externo a casa. Tal constatação pode ser exemplificada no comentário do narrador-personagem sobre a conquista de uma vaga no mercado de trabalho:

Acontecera um milagre. Um milagre à toa, mas básico para quem, como eu, não tinha pais ricos, dinheiro aplicado, imóveis nem herança e apenas tentava viver sozinho numa cidade infernal como aquela que trepidava lá fora, além da janela ainda fechada do apartamento. (ABREU, 1990, p. 11).

O "lá" sugere a existência de um espaço longínquo que contrastaria com o lugar de "dentro" da janela. Talvez por ser a cidade "infernal", a janela está "fechada". Seria esta uma forma de o jornalista se auto-proteger dos atropelos da realidade externa ou de fugir dela? A janela fechada pode, nessa linha de raciocínio, representar a resistência e a dificuldade do personagem em fazer parte do mundo da cidade. No entanto, uma análise mais detalhada da visão do narrador sobre a cidade aponta que a perspectiva sombria sobre o lugar em que vive, aos poucos, vai se entrecruzar com a própria perspectiva de vida do personagem, indicando que, na verdade, não há separação entre espaço público e privado.

Uma passagem interessante do romance sinaliza esse imbricamento entre os planos externo e interno, já que é também pelo olhar de cima, do apartamento, que o protagonista descreve a cidade como um cenário caótico, nebuloso, poluído e contaminado:

Atrás da mesa dele os vidros imundos filtravam a luz cinza da Nove de Julho. A cidade parecia metida dentro de uma cúpula de vidro embaçada de vapor. Fumaça, hálitos, suor evaporado, monóxido, vírus. (ABREU, 1990, p. 16).

O jornalista, ao destacar o caráter desorganizado e poluído da cidade, evidencia uma das facetas da metrópole moderna, a qual, segundo Hans Blumenfeld (1972), trouxe vários avanços à vida social e econômica, como o aumento do número de alternativas de emprego e variedade na mão-de-obra, mas também propiciou problemas, como a poluição do ar. Assim, a metrópole pode ser vista sob dois aspectos: um positivo e outro negativo, pois ao mesmo tempo em que provoca o crescimento, colabora para a destruição, tal como aponta a visão de Marshal Berman (1990) sobre a modernidade.

É interessante destacar ainda que, ao sinalizar a contaminação e o vírus da cidade, o protagonista não está restrito somente ao espaço urbano enquanto materialidade concreta. Está também antecipando a idéia de que a contaminação e o vírus atingem o ser humano, o que se 
confirma na seqüência do romance quando o leitor descobre a opção sexual do narradorpersonagem e a sua doença. O jornalista é um homossexual que se deixou contaminar pelo vírus da AIDS.

A homossexualidade, aliás, é um dos temas recorrentes na produção final de Caio Fernando Abreu, num período em que o escritor não separava mais suas inquietações pessoais decorrentes da sua própria contaminação pelo vírus HIV nem ocultava sua opção sexual aos leitores. Além disso, é possível relacionar a opção sexual "ex-cêntrica" ao contexto moderno, como o faz o pesquisador Bruno Souza Leal (2002). Baseado no eixo triádico "metrópole/identidade/sexualidade", que, segundo Leal, singulariza a produção literária de Caio Fernando Abreu, o ensaísta afirma que a inserção do sujeito numa metrópole, caracterizada como um espaço das multidões, em que o indivíduo entra em conflito consigo mesmo e especialmente com sua identidade, é também um fator propício para o desenvolvimento da homossexualidade. Assim, os sujeitos homoeróticos criam espaços flexíveis e estranhos ao ambiente heterocentrado e tornam-se marginalizados, o que implica a dificuldade de construção de identidades fixas.

Tal caracterização do sujeito homossexual marginalizado torna-se evidente na relação estabelecida entre o protagonista do romance de Caio Fernando Abreu e Saul, homem que mantinha um romance com Dulce Veiga, mas que também se mostrou interessado pelo jornalista, beijando-o. E ainda se evidencia no romance do jornalista com Pedro, tal como o próprio narrador descreve em carta enviada a uma amiga:

Quase dormi, não lembro. Quando acordei, ele me beijava.

O beijo de Pedro não era desses de amigo bêbado, encharcado de álcool e solidariedade masculina, carência etílica ou desespero cúmplice.

A língua de Pedro dentro da minha boca era a língua de um homem sentindo desejo por outro homem.

Ele era bonito. Todo claro, quase dourado.

Tentei afastá-lo, repetindo que nunca tinha feito aquilo. Eu gostava de mulher, eu tinha medo. Todos os medos de todos os riscos e desregramentos. (ABREU, 1990, p. 113).

A forma como o jornalista vê seu envolvimento com Pedro sinaliza ao mesmo tempo um certo desconforto e estranhamento diante de uma atitude desviante e também uma tensão motivada pelo descumprimento de regras de ordem moral e comportamental. Nesse sentido, é possível relacionar o temor do personagem às regras vigentes na sociedade moderna, visto que, mesmo sendo a metrópole um lugar favorável à sexualidade ex-cêntrica e à modernização que atinge também o plano comportamental, o que garante um status revolucionário ao contexto moderno, ainda há conservadorismo nas relações pessoais e na aceitação da diferença ou da "conduta desviante" no campo da sexualidade. É novamente a afirmação de um antagonismo social. Isso também leva a pensar a cidade tal como propõe 
Sandra Pesavento (1999) ao afirmar que "a cidade está destinada a ser centro de conflito" $(1999$, p. 8), apontando a multiplicidade de olhares e significados propiciados pela leitura da cidade.

A existência do "medo" e a certeza dos "riscos" de um "desregramento" condicionam a desestruturação do sujeito, cuja identidade passa a ser "móvel". Nessa perspectiva Bruno Leal afirma que a definição de uma identidade sexual é complexa para o indivíduo contemporâneo porque este passa a carregar consigo "um estranhamento, um sentimento de inadequação, como se toda a certeza estivesse impregnada por uma transitoriedade" (LEAL, 2002, p. 40). Nessa perspectiva, o assumir-se como homossexual é um desafio, e viver na metrópole é conviver com um descentramento do sujeito.

O personagem central do romance, por manter um comportamento discreto em relação à sua sexualidade e ter consciência do espaço conservador em que vive, não se mostra engajado ou militante na defesa da sexualidade marginal. Mas também não é indiferente aos princípios que norteiam a construção de uma identidade sexual. Sabe diferenciar vida pública e vida privada, sinalizando a possibilidade de explicitar menos a violência social contra si mesmo ao não se chocar com a "norma" sexual. Seria o jornalista um exemplo do que Silviano Santiago (2000) chama de "homossexual astucioso", aquele que não se expõe à agressão nem manifesta comportamento mimético de "automarginalização" proveniente da cultura norte-americana.

À caracterização do personagem como um ser marginal em relação à sexualidade, somam-se as descrições de outros "personagens" próprios das cidades e mais comuns nas metrópoles. São também seres marginalizados, a exemplo do flaneur identificado por Walter Benjamin ao discutir a poesia de Charles Baudelaire. Tal como na poesia do escritor francês, os sujeitos reconhecidos na narrativa também são maus trapeiros, como indica o excerto a seguir, no qual o protagonista constrói um retrato verbal dos seres que compõem um dos cenários da cidade de São Paulo:

Até encontrar um táxi, passei por dois anões, um corcunda, três cegos, quatro mancos, um homem-tronco, outro maneta, mais um enrolado em trapos como um leproso, uma negra sangrando, um velho de muletas, duas gêmeas mongolóides, de braço dado, e tantos mendigos que não consegui contar. A cenografia eram sacos de lixo com cheiro doce, moscas esvoaçando, crianças sem volta.

$\mathrm{Na}$ esquina estava um homem vestido com um macacão alpino, de chapeuzinho verde, tocando realejo para um periquito desses que tiram a sorte. (ABREU, 1990, 21-22).

Os tipos humanos encontrados pelo personagem numa de suas andanças pela cidade permitem reconhecer um traço próprio das metrópoles: a pobreza e a condição indigna de vida daqueles que não têm o seu lugar nem em relação à moradia nem quanto a reconhecimento e 
atenção. Além de estarem em espaço periférico, sem cuidados, são também periféricos. Talvez sejam tratados assim por viverem numa cidade que, na visão do protagonista, é caótica e não mantém equilíbrio entre progresso e decadência e nem está preparada para o crescimento que a atingiu. Nesse cenário onde convivem jornalistas, artistas e intelectuais, também são presentes os seres "subalternos" embora, tal como destaca o narrador, todos experienciem o caos, especialmente se o dia for chuvoso ou acontecer um temporal, momento em que as ruas ficam "alagadas, intransitáveis, a cidade em estado de calamidade, como em todas as tardes de verão" (ABREU, 1990, p. 31) e em que se imaginam "favelas desabadas, carros levados pela enxurrada, congestionamento, um edifício evacuado" (ABREU, 1990, p. 36).

A cidade como um macrocenário caótico encontra ressonância num microespaço, o do edifício onde mora o protagonista do romance de Caio Fernando Abreu. Tal como a cidade, o prédio está “contaminado”, desestruturado, decadente, frágil:

Era um edifício doente, contaminado, quase terminal. Mas continuava no mesmo lugar, ainda não tinha desmoronado. Embora, a julgar pelas rachaduras do concreto, pelas falhas cada vez mais largas no revestimento de pastilhas de cor indefinida, como feridas, espelhando-se aos poucos sobre a pele, isso fosse apenas uma questão de meses.

Velha e querida espelunca, pensei com carinho, esse tipo de carinho por um cachorro velho, cego e sarnento, enquanto passava a mão na eterna placa de em consserto pendurada pelos porteiros nordestinos na porta do elevador quebrado.

Novamente subi pelas escadas meio alagadas, que sempre me faziam lembrar de um hospital onde nunca estivera. Um hospital em quarentena, isolado por alguma peste desconhecida e mortal. (ABREU, 1990, 37).

Os termos usados para caracterizar o edifício são expressões que, indiretamente, fazem alusão ao estado emocional do personagem e também a sua condição frágil de sujeito contaminado pelo vírus da AIDS. São todos vocábulos com carga semântica negativa que colaboram para a construção de um contexto narrativo sombrio. O protagonista, como um membro da "cidade infernal", é um ser melancólico que vive numa metrópole sombria. A cidade, nesse sentido, pode ser vista como um reflexo da condição humana.

\section{O homem melancólico}

O protagonista de Onde andará Dulce Veiga? expressa uma angústia e um mal-estar não só por viver numa cidade em caos, mas também por não se sentir ajustado socialmente. Tem razões para isso: sua vida é repleta de atropelos, ou melhor, "solavancos", sua posição social não é aquela desejada, encontra dificuldades de sobrevivência e de conquista de emprego, mora num apartamento sombrio, a cidade é "infernal", e ele ainda se afasta da regra sexual, vive sozinho, não tem mais fé, convive com a doença da AIDS. Todas essas situações 
proporcionam ao personagem uma descrença em relação à vida, um sentimento de perda em relação ao passado e uma necessidade de buscar a si mesmo, de construir uma identidade, de reencontrar uma paz interior.

Para o personagem, o momento atual de sua vida é distante do passado, que era um tempo "em que tinha fé. Bons tempos aquele" (ABREU, 1990, p.11). Um tempo que contrasta com a realidade atual, com um cotidiano marcado pela rotina de não ter o que fazer, pela falta de uma vida digna, pelo fato de ser um jornalista "endividado, amargo, solitário e desiludido de quase quarenta anos" (ABREU, 1990, p. 13), pela inexistência de um emprego. Este, embora seja conquistado pelo protagonista, não o motiva nem restabelece a sua dignidade, não o faz "emergir do pântano de depressão e autopiedade onde refocilava há quase um ano" (ABREU, 1990, p. 12). Além disso, o emprego é apenas um "trabalhinho de repórter no Diário da Cidade, talvez o pior jornal do mundo" (ABREU, 1990, p. 12).

O trabalho como repórter do jornal lhe é familiar, mas não propicia uma "sensação agradável" (ABREU, 1990, p. 14) e a contaminação pelo vírus o fragiliza. O narradorpersonagem teme sua fraqueza: "vou pegar um resfriado, pensei - e não, eu não podia, o jornal, a entrevista, a febre outra vez no apartamento vazio, as pontas dos dedos buscando sinais malditos no pescoço, na nuca, nas virilhas" (ABREU, 1990, p. 32). Sua condição física e emocional são sintomas da desestruturação do personagem, de seu estado singular.

Essas angústias do narrador são indícios de uma melancolia, compreendida em seu sentido moderno, uma vez que o conceito de melancolia já recebeu muitas definições ao longo do tempo e entre os autores que se voltaram para o tema nem sempre é possível apontar um ponto convergente ${ }^{1}$, pois a discussão sobre o assunto depende do pensamento vigente da época. Partindo desse princípio, Moacyr Scliar (2003) afirma que as acepções sobre melancolia são elaboradas por haver uma "espécie de contágio psíquico" que emoldura o pensamento de uma época e de um lugar, condicionando a representação da melancolia nas artes e na literatura.

Para compreender a perspectiva melancólica subjacente à construção narrativa do romance de Caio Fernando Abreu, é possível recorrer ao pensamento de Walter Benjamin,

\footnotetext{
${ }^{1} \mathrm{Na}$ Antigüidade ou período clássico, Hipócrates, Aristóteles e Constantinus Africanus formularam proposições acerca do conceito de melancolia. Durante a Idade Média, as teorias dos árabes ganharam força, e a melancolia foi vista sob a influência maléfica do planeta Saturno. Tal associação é abordada por Raymond Klibansky, Erwin Panofsky e Fritz Saxl em obra sobre saturno e melancolia. O cenário do Renascimento foi marcado por profundas modificações psicológicas e tecnológicas que reativaram a reflexão sobre a melancolia. No Romantismo, o estado melancólico passou a ser explorado por poetas e prosadores, que viam na experiência da perda do objeto amado um impulso para a melancolia. E no século XX pensadores como Walter Benjamin, Julia Kristeva e Sigmund Freud apresentam reflexões modernas sobre o tema que possibilitam pensar uma relação entre obra de arte e melancolia.
} 
que, ao analisar o drama barroco alemão, apontou que a impossibilidade de conciliar termos antitéticos determina a articulação do conceito de melancolia. Além disso, segundo ao autor, a miséria da condição humana acarreta a melancolia, que tem no procedimento alegórico uma forma de representação eficaz no sentido de que indica a face "doente" da história. A fragmentação formal, que é um traço da alegoria, é, nesse sentido, um sinal da perspectiva melancólica. A melancolia na concepção benjaminiana é entendida como uma manifestação de uma consciência acerca da sujeição do homem ao seu destino, pois "as ações humanas foram privadas de todo valor. Algo de novo surgiu: um mundo vazio.” (1984, p. 162).

O pensamento do teórico alemão pode ser aproximado das vivências do personagem de Caio Fernando Abreu através da identificação do caráter vazio da vida do jornalista, uma vida "sem graça", com uma série de "solavancos", uma vida sem "força e fé", na qual o personagem se mostra preso ao seu destino, impossibilitado de encontrar uma saída para as suas próprias angústias, de buscar um equilíbrio espiritual e também de fugir do seu descentramento. Um trecho que permite tal afirmação é o que relata a aproximação, através de cartas, do jornalista com Lídia, amiga, que, diferentemente dele, alcançou a paz e fugiu da cidade caótica:

Peguei a carta no chão, olhei o remetente. Era Lídia, provavelmente falando outra vez de todas aquelas igrejas coloniais, paredes brancas, portas e janelas azul-marinho, montanhas e vacas de Diamantina, Sabará ou Mariana. De como finalmente ela tinha descoberto a paz \& o equilíbrio $\&$ do quanto estava feliz por cair fora de São Paulo \& o que afinal eu continuava procurando nesta cidade poluída, maligna \& amaldiçoada? (ABREU, 1990, p. 40).

O personagem, de certa forma, projeta-se na amiga, quer ter uma vida como a dela, mas não consegue porque antes precisa encontrar a si mesmo, construir uma identidade, procurar o "real". Ao tomar ciência da vida que queria ter e da condição real de sua existência, o personagem parece lamentar o seu desassossego numa atitude característica dos sujeitos melancólicos apontados por Walter Benjamin (1984). A melancolia é comum aos seres ativos, para os quais o ato contemplativo dá lugar à criticidade.

Como um ser da metrópole, o jornalista também assiste ao desenvolvimento da cidade e à proliferação de produções culturais, às quais constantemente o narrador-personagem faz referência, criando um romance repleto de intertextos. Estas são apresentadas através de "colagens" que visam não só a apresentar a cidade, mas também a indicar traços significativos da constituição do sujeito, que é, por excelência, fragmentado como a cidade. Nas palavras de Bruno Leal, “a metrópole (...) é inscrita na narrativa de Caio Fernando Abreu através de referências a lugares reais como também de fragmentos de suas realidades culturais, sejam 
elas intra ou internacionais" (2001, p. 40) e a falta de integração dos personagens revela "uma paisagem urbana marcada pela fragmentação" (2001, p. 62).

A fragmentação da cidade e a fragmentação do narrador-personagem do romance são percebidas pelo jornalista, que tem consciência acerca da sua condição de ser desintegrado, do ser sem lugar algum, do seu descentramento. Ele define a sua vida como um conjunto de "peças", com as quais, segundo ele, seria possível

formar quase uma história, que interrompia-se bruscamente para continuar ou não em mais três ou quatro peças ligadas a outras que nada tinham a ver com aquelas primeiras. Outras restavam solitárias, sem conexão com nada em volta (ABREU, 1990, 56).

Pela descrição, a vida do jornalista parece ser vazia e sem objetivo ou planejamento, mais um motivo para justificar a sua melancolia.

A idéia de vazio existencial encontra respaldo pela incerteza do personagem, pela fluidez de suas convicções, pela tentativa de fuga das cidades por onde ela passava, pela instabilidade decorrente do tempo, pela dificuldade de organizar sua vida e criar laços de afeto:

À medida que o tempo passava, eu fugia, jamais um ano na mesma cidade, eu viajava para não manter laços - afetivos, gordurosos -, para não voltar nunca, e sempre acabava voltando para cidades que já não eram as mesmas, para pessoas de vidas lineares, ordenadas, em cujo traçado definido não haveria mais lugar para mim (ABREU, 1990, p. 56).

É a representação de um mundo com o qual o personagem não se identifica, seu deslocamento é inevitável e sua angústia, insubstituível. É ainda o indício de uma crise que atinge a subjetividade do protagonista e condiciona a melancolia, já que esta é constante em tempos de crise, especialmente numa sociedade em que os valores (sociais, sexuais, culturais, morais, etc) estão em conflito. Considerando que, conforme Julia Kristeva, em nossa vida social há uma "lista de desgraças que nos oprimem todos os dias" (1989, p. 11), é natural uma "existência desvitalizada" que conduza a um esforço para a morte e que a melancolia seja resultante da não assimilação da ausência de um objeto amado, outrora perdido. A melancolia, nesse sentido, assinala que o sujeito não sabe perder ou não consegue absorver uma perda.

Em Onde andará Dulce Veiga?, o personagem central lamenta a perda de um "tempo bom", de força e de fé e essa dificuldade de aceitar um novo "tempo" é fator que impede o protagonista de se sentir feliz e encontrar a paz. No entanto, no decorrer da narrativa, é possível apreender que a recuperação ou reconstrução desse estágio anterior e a conseqüente reestruturação do personagem deve passar primeiro pela reconstrução de sua identidade. Esta pode ser alcançada no momento em que ele, ao encontrar a cantora desaparecida (Dulce Veiga), encontra a si mesmo. É nesse sentido que Bruno Leal enfatiza que "Ao tomar para si a 
pergunta-título, o protagonista tenta resolver a crise (social, sexual) em que se encontra e restabelecer ligações com o mundo a sua volta.” (2001, p. 43).

Enquanto o protagonista não encontra Dulce Veiga, fica a remontar as 'peças' de sua trajetória pessoal, formando uma narrativa de cunho fragmentado, que, na verdade, tem correspondência com o estado psíquico do personagem, pois, além de uma intolerância à perda, o melancólico expressa uma dificuldade de comunicação, que se assemelha a uma problematização da linguagem e que constitui, em termos de estrutura narrativa, a forma fragmentada. Considerando isso, pode ser entendida a estrutura do romance de Caio Fernando Abreu. O modo como a narrativa está disposta não segue uma seqüência temática de ordem lógico-causal porque o movimento da obra não prioriza uma organização linear.

Os capítulos com temas e formas distintos impedem uma identificação de uma tendência estético-formal única em cada segmento. O livro não busca traçar uma unidade estanque entre as partes, mas, pelo contrário, procura suscitar no leitor a percepção de que a pluralidade (de formas, temas e sentidos) é um recurso estético que propõe a "montagem" da obra, ou seja, a articulação entre as suas partes e, conseqüentemente, uma interpretação. Essa idéia de montagem, aliás, está interiorizada pela apresentação da vida do personagem e também pela forma como ele descreve a sua trajetória pessoal, marcada pela experiência de perda, pela melancolia. Talvez por isso, o subtítulo da obra sugere um "Romance B", que remonta não a busca pela cantora, mas a busca do protagonista pelo seu próprio "eu".

É possível ainda formular a partir disso que a fragmentação da forma narrativa (evidenciada também na coexistência do romance literal e do romance paralelo - o romance B) em Onde andará Dulce Veiga? é motivada por uma perspectiva melancólica, cabendo à linguagem e estrutura narrativa a "tradução" dessa condição do narrador-protagonista. Cabe, então, fazer uma leitura da condição melancólica associada à fragmentação narrativa como resultado de uma leitura na qual o narrador-protagonista discorre sobre a sua vida, o seu espaço, a sua cidade em contraposição a uma leitura mais explícita, marcada pelo tom de uma história policial concretizada pela trabalho de detetive que o jornalista faz para encontrar a artista desaparecida. É a busca pela alteridade, apontada por Fernando Arenas (2003) como um mote da criação de Caio Fernando Abreu. Para o crítico, o escritor gaúcho recompõe o contexto sócio-político brasileiro do final do século XX, dando destaque para o sentimento de desespero resultante do regime ditatorial e também para a esperança de democracia, e insere sua obra num grupo de expressões artísticas e culturais que registram o período dramático do processo de transição política no Brasil. 
Essa perspectiva crítica embasa a leitura proposta para Onde andará Dulce Veiga?. Fernando Arenas associa a trama do romance com a situação sociopolítica do país e com o processo de "cultura transnacional" que atinge São Paulo, espaço onde se desenvolve grande parte da narrativa. Segundo Arenas, o repórter que sai em busca de uma cantora brasileira famosa desaparecida acaba por descobrir a sua própria imagem, uma imagem de solidão e medo, com sonhos ideológicos, pessoais e profissionais frustrados, assim como os de toda a sua geração. No entanto, circunscrever a obra de Caio Fernando Abreu como a representação de um determinado período histórico brasileiro pode significar a limitação do alcance da obra, que pode ser lida também como uma representação dos tempos modernos, que têm início muito antes do século XX, nos quais a cidade e a metrópole assumem papel importante. Isso porque elas condensam os elementos fundamentais da modernidade, discutidos por Marshall Berman (1990).

Em sua obra sobre a modernidade, Marshall Berman (1990) assinala a existência de uma ambigüidade caracterizada por movimentos antagônicos de transformação e desenvolvimento da sociedade e de desorientação e desintegração da vida moderna, o que constitui, segundo ele, "o terror da vida que se desfaz em pedaços" e "uma vida de paradoxo e contradição" (1990, p. 13). Uma contradição - também chamada de 'dialética da modernização e do modernismo' - evidenciada num contexto que se caracteriza ao mesmo tempo por ser revolucionário e conservador, por unir a espécie humana e provocar a sua "desunidade", por propiciar alegria e angústia. Essa modernidade, dividida pelo autor em três fases - do início do século XVI até o século XX -, alcança o ápice do desenvolvimento tecnológico e a industrialização que deveriam dar melhor qualidade de vida ao homem, mas este se sente aprisionado, perde sua identidade e sua subjetividade fragmenta-se. Como se vê, Berman acrescenta à descrição dos tempos modernos, a existência de um certo 'mal-estar' coletivo diante de uma época marcada pelo paradoxo.

Nessa perspectiva, os desconfortos vividos pelo personagem central do romance assinalam um imaginário do espaço urbano representado por uma cidade que, segundo Laymert Garci dos Santos, "explode implodindo, se estilhaça como cidade fundindo num magma caótico cada um de seus fragmentos" (2002, p. 116). Os desconfortos também motivam a melancolia, o que autoriza a leitura do romance de Caio Fernando Abreu como uma representação da cidade moderna e do homem melancólico, numa alusão à reflexão exposta por Reinaldo Marques (1998) ao reconhecer na produção de poetas mineiros uma melancolia como "metáfora esclarecedora das relações do poeta com o lugar problemático que lhe cabe no espaço da modernidade" (1998, p. 159). Caio, através da criação de um 
personagem melancólico, sugere que a melancolia do homem moderno resulta da situação caótica da cidade, a qual não possibilita a unidade do ser, mas, ao contrário, a sua fragmentação. Uma fragmentação do sujeito a qual, no romance analisado, encontra um paralelismo na forma literária, pois o caos e a falta de linearidade marcam a trajetória do jornalista e a construção narrativa.

\section{Referências}

ARENAS, Fernando. Utopias of otherness: nationhood and subjectivity in Portugal and Brazil. Minneapolis: University of Minnesota Press, 2003.

BENJAMIN, Walter. Origem do drama barroco alemão. São Paulo: Brasiliense, 1984.

BERMAN, Marshall. Tudo que é sólido desmancha no ar: a aventura da modernidade. 8. ed. São Paulo: Schwarcz, 1990.

BLUMENFELD, Hans. A metrópole moderna. In: DAVIS, Kingsley, et al. Cidade: a urbanização da humanidade. 2. ed. Rio de Janeiro: Zahar Editores, 1972.

GOMES, Renato Cordeiro. Representações da cidade na narrativa brasileira pós-moderna: esgotamento da cena moderna?. Alceu, n. 1, p. 64-74, jul./dez. 2000.

HOHLFELDT, Antônio. Literatura e vida social. Porto Alegre: Ed. da Universidade/UFRGS, 1996.

KRISTEVA, Julia. Sol negro: depressão e melancolia. Rio de Janeiro: Rocco, 1989.

LEAL, Bruno Souza. Caio Fernando Abreu, a metrópole e a paixão do estrangeiro: contos, identidade e sexualidade em trânsito. São Paulo: Annablume, 2002.

. A literatura como cartografia textual: Onde andará Dulce Veiga?, de Caio Fernando Abreu. Brasil/Brazil, n. 25, Porto Alegre, EDIPUCRS, p. 39-67, 2001.

MARQUES, Reinaldo. Tempos modernos, poetas melancólicos. In: SOUZA, Eneida Maria (org.). Modernidades tardias. Belo Horizonte: ED. UFMG, 1998.

PESAVENTO, Sandra Jatahy.O imaginário da cidade: visões literárias do urbano: Paris, Rio de Janeiro, Porto Alegre. Porto Alegre: UFRGS, 1999.

SANTIAGO, Silviano. O homossexual astucioso. Brasil/Brazil, n. 23, Porto Alegre, EDIPUCRS, p. 7-18, 2000.

SANTOS, Laymert Garcia dos. São Paulo ao é mais ima cidade. In: PALLAMIN, VAERA; LUDEMANN, Marina (orgs.) Cidade e cultura: esfera pública e transformação urbana. São Paulo: Estação Liberdade, 2002. 
SCLIAR, Moacyr. Saturno nos trópicos: a melancolia européia chega ao Brasil. São Paulo: Companhia das Letras, 2003. 